\title{
Infrared Thermal Imaging as Innovative Techniques with Eco-physiological Traits for Monitoring Water Stress in Wheat
}

\author{
Bayoumi, T.Y." ${ }^{* 1}$ Amal M. Abd EL-Mageed ${ }^{2}$; Enas S. Ibrahim² and Soad A. Mahmoud ${ }^{1}$ \\ ${ }^{1}$ Agronomy Department, Faculty of Agriculture, Suez Canal University, 41522 Ismailia, Egypt \\ ${ }^{2}$ Botany Department, Faculty of Agriculture, Suez Canal University, 41522 Ismailia, Egypt
}

Received: $20 / 12 / 2015$

\begin{abstract}
The association of Infrared thermal imaging and specific target traits for drought tolerance (presence of awns, Normalized Difference Vegetative Index (NDVI), Relative Water Content (RWC), leaf area) with yield performance under three water regimes was analyzed utilizing wheat genotypes in two seasons (2012/2013 and 2013/2014). In this study eight genotypes of bread wheat were used for screening them under three water regimes; control $100 \%$ Field Capacity (FC), 75\% FC and 50\% FC. The presence of awns had a significant effect on yield loss under drought amongst wheat genotypes. Moreover, an infrared crop water stress index was calculated in the main water requirement stage. RWC was determined to give indication on the plant water status during the experiment. RWC ranged from $47.2 \%$ to $76.5 \%$ for water stress $(50 \%$ FC). NDVI ranged from 0.31 (Maser 2) to $0.49(\mathrm{H} 2)$ under water stress $50 \%$ FC. This result indicated that hybrid $(\mathrm{H} 2)$ had the greatest green biomass and could be considered as a drought tolerant genotype. Temperatures of canopies can be used as indicators of stomatal closure in response to soil water deficit. It was found that thermal imaging can distinguish between stressed and non-stressed canopies, and even between deficit water treatments. Leaf temperature $\left(\mathrm{T}_{\text {leaf }}\right)$ varied between water stress treatments and among the wheat genotypes within the same water treatment. Where, $\mathrm{T}$ leaf was ranged from 21.9 to $25.3^{\circ} \mathrm{C}$ for $50 \% \mathrm{FC}$ treatment. Similar observations were noticed for the other water treatments. Indicating that the other physiological mechanism could be influenced on the behavior of genotypes due to water stress and subsequently leaf temperature was affected. Variation of the distribution of temperatures within canopies was found to be a reliable indicator of water stress. It could be concluded that combining thermal camera technology with physiological traits was sufficiently to predict wheat production under water stress.
\end{abstract}

Keywords: Drought, Relative water content, Normalized Difference Vegetative Index

\section{INTRODUCTION}

Food crises in less-developed countries have been noted to be the main obstacle to economic development. Egypt suffers from such a crisis because the population increases rapidly, while food production cannot respond to such an increase. Water scarcity in Egypt is a well known and alarming problem. Egypt face severe water scarcity due to limited opportunities for the exploitation of new sources of water coupled with the rapidly growing demand for water resources.

Wheat is an important crop occupying around $16 \%$ of the arable lands of the world (FAO, 2014), with increasing world demand and associated shortages in production in many countries. In this regard seasonal drought has always been a problem for many countries. Egypt is located in a dry region which does not allow the rain fed system of crop production to perform well. . In future years breeding programs must consider and select for improved water use efficiency in newly released varieties. In this regard screening for more drought tolerant wheat varieties, which are able to produce an acceptable yield under water stress must be considered. However, droughts reduce crop growth and increase mortality rates, thereby shifting the competitive advantage toward genotypes with greater drought stress tolerance (Brenes-Arguedas et al., 2011).

Eco-physiological measurements can be used to identify crop parameters for selecting them for water stress, thus improving water use efficiency. Relative water content, among others, is considered one of the most reliable indicators of crop water status, even if measurements are labor-intensive and time-consuming. Non-destructive and fast methods to assess the crop water status are therefore desirable (Dawson et al., 2002). In this context, proximal or remote sensing of vegetation constitutes non-invasive methodologies to monitor physical and physiological characteristics of plants and to evaluate the effects of environmental stress on plant performance (Jones and Vaughan, 2010). Proximal sensing techniques allow to obtain observations at different scales (from single leaves/seedlings to entire branches/plants on to trees and on to fields), useful for direct or indirect assess of the dynamic and spatial variability of various ecophysiological processes.

Thermal sensing with high-resolution thermal imaging systems had limited practical use in agriculture until recently, because of the technological problems presented by the bulk of cooled IR systems that could provide the required spatial and thermal accuracy. The recent development of uncooled thermal imaging systems based on micro-bolometers reduced the cost of the systems and, more importantly, made them easy to use in field conditions. Their relatively high spatial and thermal resolution enables radiometric measurement of temperatures with typical accuracy of $0.1^{\circ} \mathrm{C}$. More recently, approaches have been developed in attempts to improve the sensitivity of infrared estimation of crop stress indices by the use of either dry (Kursar et al., 2009) or wet and dry (Jones, 1999; Jones et al., 2009) reference surfaces. One of the best known indices for evaluating crop water stress is the Crop Water Stress Index (CWSI), which expresses the difference between "well-watered baseline' 'and "total stress", temperatures and is normalized against vapor pressure deficit (Idso, 1982; Jackson et al., 1996; Jones et al., 
2002). The objectives of this work were to evaluate thermal imaging as a tool for distinguishing between stressed and unstressed plants, and to optimize thermal imaging for determining plant responses to water deficits in the field. In addition to, some ecophysiological criteria were estimated.

\section{MATERIALS AND METHODS}

Two field experiments were conducted at the experimental farm of Suez Canal University, Ismailia governorate, Egypt to three water regimes during $2012 / 2013$ and 2013/2014 to investigate the behavior of eight wheat genotypes grown under field condition. These genotypes Included three Egyptian cultivars (Maser 2, Gemmiza 10 and Sids 13), three lines (Line 1, Line 2, Line 3) and two hybrids H1 (Line 1 x Sakha 93 and H2 (Line 1 x Giza 167). Drought stress treatments were applied by preventing irrigation to maintain field capacity of $75 \%$ and $50 \%$, in addition to control treatment, where, soil moisture was maintained to field capacity $(100 \%)$ until harvest. All suggested agricultural practices were followed as and when required. The experimental plot consisted of four rows, $3 \mathrm{~m}$ long, row to row and plant to plant spacing was 30 and $5 \mathrm{~cm}$, respectively.

\section{Growth measurements}

Ten guarded plants were randomly chosen from each plot to determine shoot length, awn length, Total leaf area/plant $\left(\mathrm{cm}^{2}\right)$, spike length $(\mathrm{cm}), 1000$-kernel weight $(\mathrm{g})$, and, grain yield per square meter.

\section{Eco-physiological traits \\ Relative water content (RWC)}

Leaf relative water content (RWC) was proposed as a better indicator of water status. RWC, through its relation to cell volume, may more closely reflect the balance between water supply to the leaf and transpiration rate. RWC was determined according to Schonfeld et al. (1988) for combined analysis for both seasons using the following equation:

$$
\text { RWC } \%=\frac{\text { Fresh weight }- \text { dry weight }}{\text { Turgid weight }- \text { dry weight }} \times 100
$$

\section{The normalized difference vegetation index (NDVI)}

The NDVI of the total plant biomass in each plot was measured at heading stage by means of a portable Green Seeker TM spectroradiometer (Trimple, USA). The sensor head was placed $70 \mathrm{~cm}$ above the surface of the plot, covering the total area of the plants and about 10 NDVI measurements were taken at each plot. The averaged NDVI measurements were soil-adjusted by subtracting NDVI measurements taken in empty plot. The NDVI, in the range of -1 to 1 , is derived from red and near-infrared bands of remotely sensed images(NIR - RED)/ (NIR + RED).

\section{Thermal image acquisition}

Thermal images of the plots were taken with infrared thermal cameraTi-32(Fluke Thermography, Germany) equipped with a 320 x 240 pixel microbolometer sensor, sensitive in the spectral range of $7.5-13 \mu \mathrm{m}$.The canopy height was about $1 \mathrm{~m}$, Images were analyzed in Ti-32 Pro software (Infrared Solutions); Emissivity for measurements of leaves and plant canopies was set at 0.96 while transmission correction was $85 \%$. For more accuracy, the span of auto adjusted thermal image is manually set, in addition to level of the displayed as an important camera feature in order to detect maximum and minimum temperature of the entire display (Wilcox and Makowski, 2014).

\section{Thermal indices and stomatal conductance}

Where individual leaves were imaged in $2013 / 2014$, dry and wet references were used to mimic leaves with fully closed and fully open stomata, respectively (Jones et al., 2009). These references were determined for wheat leaves, cut from the canopy prior to measurements and placed close to the leaves of interest. Wet reference leaves were sprayed with water on both sides, regularly, to maintain their moisture. Dry reference leaves were covered in petroleum jelly (Vaseline) on both sides. The temperatures of these references were obtained $\left(\mathrm{T}_{\text {dry }}\right.$ and $\left.\mathrm{T}_{\text {wet }}\right)$ and used in conjunction with leaf temperatures to obtain thermal indices.

The index $\mathrm{I}_{\mathrm{G}}$ was proportional to the leaf conductance to water vapor transfer which was calculated from leaf temperatures as follow:

$\mathrm{I}_{\mathrm{G}}=\left(\mathrm{T}_{\text {dry }}-\mathrm{T}_{\text {leaf }}\right) /\left(\mathrm{T}_{\text {leaf }}-\mathrm{T}_{\text {wet }}\right)$. This index is theoretically proportional to stomatal conductance (gs) (Cohen et al., 2005). An index analogous to Idso's (1982) crop water stress index (CWSI) was also calculated, where in this case $\mathrm{CWSI}=\left(\mathrm{T}_{\text {dry }}-\mathrm{T}_{\text {leaf }}\right) /\left(\mathrm{T}_{\text {dry }}-\mathrm{T}_{\text {wet }}\right)$.

\section{Statistical analysis}

The experiment was conducted in a randomized complete block design with three replicates. Each field trial was analyzed separately, because of differences in salinity level. Data were statistically analyzed using the appropriate analysis of variance according to Steel et al. (1997). Combined analysis of variance over the two seasons was applied after using the homogeneity test. To confirm the relative importance of the various characters, a set of genetic parameters (genotypic and phenotypic coefficient of variability and heritability in broad sense were calculated according to Hallauer and Miranda (1988). A computer program Genstat 8 Rel.PL16 was used for analyzing data.

\section{RESULTS AND DISCUSSION}

\section{The effect of water stress on growth measurements}

Plant eco-physiology may help us to identify traits or set of traits that improving yield under stress conditions. The results in Table (1) showed that subjected wheat genotypes to water stress caused a significant reduction in plant height and total leaf area/ plant. There were significant differences among wheat genotypes for both characters. The relative percentage of decreases (RD \%) for plant height due to water stress were $34.1 \%$ and $31.2 \%$ for $2012 / 2013$ and $2013 / 2014$, respectively. While, the leaf area/plant reduced under sever water stress ( $50 \% \mathrm{FC})$ compared to $100 \% \mathrm{FC}$ by $42.2 \%$ and $36 \%$ for both season respectively. This reduction in plant height, total leaf area/plant under stress conditions might be due to the lack of water 
absorbed and inhibition of photosynthetic efficiency under high water stress conditions. Also, reduction of leaf area is an important adaptive mechanism for drought stress and is usually the first strategy for a plant adopts when water becomes limiting. Many studies have been discussed the effect of water stress on characters of vegetative plant growth and given the same results (Quarrie et al., 1999; Bayoumi et al., 2002). Subjecting wheat genotypes to water stress decreased remarkably spike length, and 1000-kernel weight as shown in Table
(2). Over both seasons, the reduction percentages were $26.6 \%$ for spike length, and $19.3 \%$ for 1000 -kernel weight. These results indicated that 1000-kernel weight were affected less by stress, while, the harmful effect was noticed on spike length. Ehdaie et al. (1988) reported similar responses for these components under stress conditions. Moreover, these responses to stress environment could be explained differences in the balance between photosynthetic source and production sink.

Table (1): Effect of various water stress on plant height and leaf area for wheat genotypes in 2012/2013 and 2013/2014 seasons.

\begin{tabular}{|c|c|c|c|c|c|c|c|c|c|c|c|c|}
\hline \multirow{3}{*}{$\begin{array}{l}\text { Genotypes } \\
\text { Water stress }\end{array}$} & \multicolumn{6}{|c|}{ Plant Height (Cm) } & \multicolumn{6}{|c|}{ Leaf Area $\left(\mathrm{Cm}^{2}\right)$} \\
\hline & \multicolumn{3}{|c|}{$2012 / 2013$} & \multicolumn{3}{|c|}{$2013 / 2014$} & \multicolumn{3}{|c|}{$2012 / 2013$} & \multicolumn{3}{|c|}{$2013 / 2014$} \\
\hline & $\begin{array}{c}100 \\
\% \mathrm{FC}\end{array}$ & $\begin{array}{c}75 \\
\% \mathrm{FC}\end{array}$ & $\begin{array}{c}50 \\
\% \mathrm{FC}\end{array}$ & $\begin{array}{c}100 \\
\% \mathrm{FC}\end{array}$ & $\begin{array}{c}75 \\
\% \mathrm{FC}\end{array}$ & $\begin{array}{c}50 \\
\% \mathrm{FC}\end{array}$ & $\begin{array}{c}100 \\
\% \mathrm{FC}\end{array}$ & $\begin{array}{c}75 \\
\% \mathrm{FC}\end{array}$ & $\begin{array}{c}50 \\
\% \mathrm{FC}\end{array}$ & $\begin{array}{c}100 \\
\% \mathrm{FC}\end{array}$ & $\begin{array}{c}75 \\
\% \mathrm{FC}\end{array}$ & $\begin{array}{c}50 \\
\% \mathrm{FC} \\
\end{array}$ \\
\hline Gemmiza 10 & 86.7 & 84.3 & 70.0 & 88.5 & 85.6 & 72.9 & 45.0 & 39.1 & 21.7 & 48.9 & 40.6 & 25.8 \\
\hline L1 & 109.0 & 78.3 & 72.3 & 110.6 & 80.2 & 75.4 & 56.3 & 31.3 & 26.7 & 60.3 & 37.9 & 30.4 \\
\hline L2 & 121.7 & 114.0 & 69.0 & 125.2 & 115.5 & 71.2 & 68.7 & 55.8 & 43.3 & 70.3 & 58.6 & 45.2 \\
\hline L3 & 92.0 & 65.3 & 57.7 & 94.2 & 70.3 & 60.8 & 28.4 & 16.3 & 11.0 & 35.2 & 22.3 & 18.2 \\
\hline Sids 13 & 86.3 & 77.7 & 62.0 & 90.1 & 80.2 & 66.8 & 35.8 & 24.0 & 20.3 & 39.5 & 28.2 & 23.2 \\
\hline Maser 2 & 102.3 & 98.3 & 65.0 & 105.6 & 91.5 & 70.5 & 58.5 & 36.6 & 34.3 & 60.2 & 40.2 & 35.1 \\
\hline $\mathrm{H} 1$ & 105.3 & 92.3 & 63.0 & 107.3 & 95.2 & 78.2 & 52.7 & 48.3 & 40.3 & 40.3 & 49.2 & 42.3 \\
\hline $\mathrm{H} 2$ & 111.3 & 86.7 & 75.7 & 115.2 & 90.2 & 79.5 & 62.3 & 47.7 & 38.0 & 66.2 & 65.4 & 48.9 \\
\hline LSD & 1.2 & 1.8 & 1.6 & 2.3 & 2.1 & 2.5 & 3.4 & 3.8 & 2.7 & 4.3 & 4.4 & 4.8 \\
\hline $\mathrm{RD} \%$ & & 34.1 & & & 31.2 & & & 42.2 & & & 36.0 & \\
\hline
\end{tabular}

$\mathrm{RD} \%$, relative percentage of reduction

Table (2): Effect of various water stress on spike length and 1000 kernel weight for wheat genotypes in 2012/2013 and $2013 / 2014$ seasons

\begin{tabular}{|c|c|c|c|c|c|c|c|c|c|c|c|c|}
\hline \multirow{3}{*}{$\begin{array}{l}\text { Genotypes } \\
\text { Water stress }\end{array}$} & \multicolumn{6}{|c|}{ Spike Length (Cm) } & \multicolumn{6}{|c|}{ 1000- kernel weight (g) } \\
\hline & \multicolumn{3}{|c|}{$2012 / 2013$} & \multicolumn{3}{|c|}{$2013 / 2014$} & \multicolumn{3}{|c|}{$2012 / 2013$} & \multicolumn{3}{|c|}{$2013 / 2014$} \\
\hline & $\begin{array}{c}100 \\
\% \mathrm{FC}\end{array}$ & $\begin{array}{c}75 \\
\% \mathrm{FC}\end{array}$ & $\begin{array}{c}50 \\
\% \mathrm{FC}\end{array}$ & $\begin{array}{c}100 \\
\% \mathrm{FC}\end{array}$ & $\begin{array}{c}75 \\
\% \mathrm{FC}\end{array}$ & $\begin{array}{c}50 \\
\% \mathrm{FC}\end{array}$ & $\begin{array}{c}100 \\
\% \mathrm{FC}\end{array}$ & $\begin{array}{c}75 \\
\% \mathrm{FC}\end{array}$ & $\begin{array}{c}50 \\
\% \mathrm{FC}\end{array}$ & $\begin{array}{c}100 \\
\% \mathrm{FC}\end{array}$ & $\begin{array}{c}75 \\
\% \mathrm{FC}\end{array}$ & $\begin{array}{c}50 \\
\% \mathrm{FC}\end{array}$ \\
\hline Gemmiza 10 & 11 & 9.6 & 9 & 12.2 & 9.7 & 9.1 & 54 & 46.3 & 42.3 & 55.2 & 47.1 & 42.3 \\
\hline L1 & 10.7 & 10.7 & 8.7 & 11.3 & 10.6 & 8.8 & 50 & 47.7 & 41.2 & 51.2 & 47.9 & 41.9 \\
\hline L2 & 11.3 & 8.7 & 8.7 & 12.6 & 9.8 & 8.7 & 54.7 & 45.9 & 41.4 & 55.3 & 46.2 & 41.5 \\
\hline L3 & 10 & 10.3 & 8.7 & 10.3 & 10.4 & 8.9 & 44.7 & 41 & 32.1 & 46.3 & 42.8 & 32.8 \\
\hline Sids 13 & 10.1 & 9.2 & 7 & 10.9 & 9.8 & 7.5 & 44.1 & 41 & 38.3 & 45.2 & 43.1 & 39.7 \\
\hline Maser 2 & 10.3 & 10 & 7.7 & 10.4 & 10 & 7.8 & 46 & 44 & 37.9 & 47.1 & 45.6 & 38.5 \\
\hline $\mathrm{H} 1$ & 11 & 10 & 6 & 11.3 & 10.2 & 7.7 & 51.7 & 49.8 & 41.7 & 52.3 & 49.8 & 43.2 \\
\hline $\mathrm{H} 2$ & 11.7 & 10.3 & 7.7 & 11.7 & 10.4 & 7.9 & 50 & 48 & 46.3 & 55.3 & 48.9 & 46.9 \\
\hline LSD & 0.08 & 0.11 & 0.12 & 0.18 & 0.21 & 0.24 & 1.1 & 1.2 & 1.4 & 1.3 & 0.9 & 0.8 \\
\hline RD\% & & 26.4 & & & 26.8 & & & 18.7 & & & 19.8 & \\
\hline
\end{tabular}




\section{Effect of awns on yield response to drought}

There was an effect of awns on the grain yield loss of the eight genotypes under non stress and stress in both seasons (2012/2013 and 2013/2014) Figure (1). Averaging across years indicated that, the yield of awned genotypes was reduced under drought by $449.4 \mathrm{Kg} / \mathrm{m}^{2}$ compared to $371.7 \mathrm{Kg} / \mathrm{m}^{2}$ for unawned genotypes. Awned genotypes maintained ears $\mathrm{m}^{-2}$ better under drought $(\mathrm{p} \leq 0.01)$. The regression coefficient $\left(\mathrm{R}^{2}\right.$ $=0.509$ ) was significant for the relationship between grain yield and awned and unwned genotypes (Fig 1). Increasing the amount of awn tissues will also increase the shading of leaves and decrease the temperature of leaves. While, there is also the possibility that during differentiation of the spike among genotypes, excessive awn tissue may utilize assimilate that would otherwise be used for the formation of additional florets.

Long awns have been demonstrated to be a useful selection indicator in wheat for improved production in hot, dry environments (Blum, 1986) where impaired leaf function due to abiotic stress is common. In the UK the presence of awns was selected against in the second half of the 20th century (through selection for the awn suppressor at the locus B1 on chromosome 5A) and virtually all UK modern cultivars are unawned (Snape et al., 2001). It is not certain why awnless phenotypes predominate in the UK. It can be hypothesized this was because of association with desirable genes linked to the awn inhibitor.

\section{The effect of water stress on Relative Water Content (RWC)}

Relative water content was determined to give indication on the plant water status during the experiment. Figure (2) showed significant differences among wheat genotypes in RWC. RWC ranged from 47.2 to 76.5 for water stress $50 \%$ FC. Genotypes L1, L2, H1 and $\mathrm{H} 2$ had the highest values of RWC under stress conditions. These genotypes which maintained higher RWC under stress conditions believed to be more drought tolerant than others. Moreover, it can be concluded that these genotypes which tend to arise their RWC, they acquire their tolerance from great solute accumulation and metabolites, hence, osmotic adjustment occurred with higher RWC (Ritchie et al., 1990).

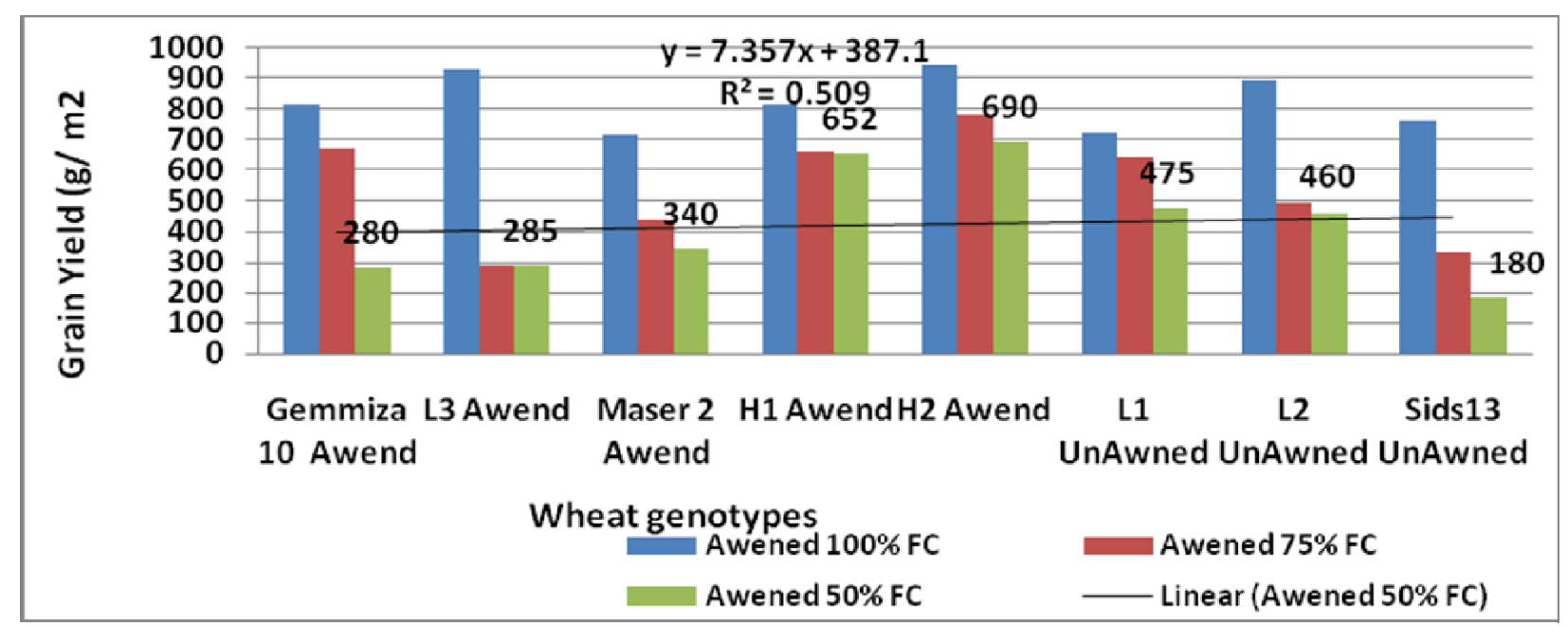

Fig. (1): The effect of awns on grain yield for wheat genotypes under water stress for combined analysis

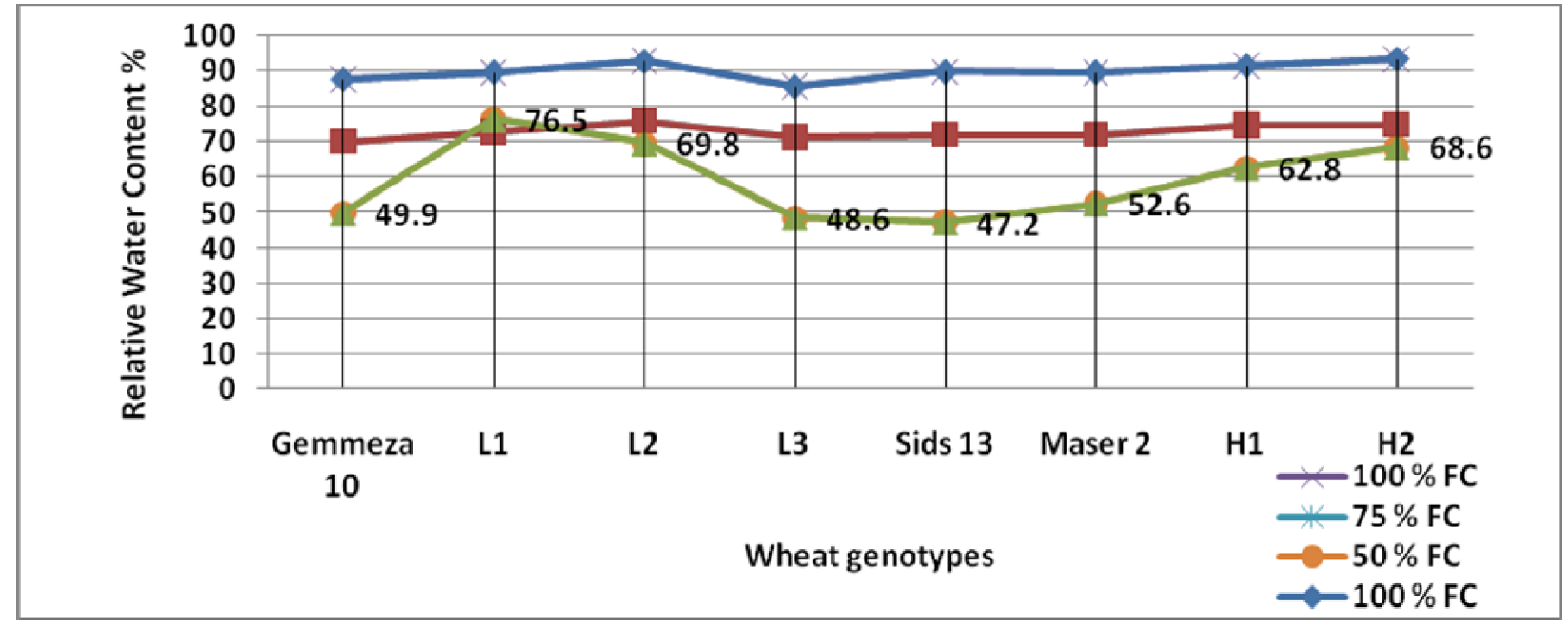

Fig. (2): The effect of water stress on relative water content for wheat genotypes for combined analysis 


\section{The effect of water stress on NDVI}

The normalized difference vegetation index (NDVI) is gaining popularity as a complementary selection tool for drought tolerance. Our results showed that NDVI significantly correlated with grain yield $\left(\mathrm{R}^{2}\right.$ $=0.720$ ) for wheat genotypes under different water stress treatments (Fig. 3). NDVI ranged from 0.31 (Maser 2) to $0.49(\mathrm{H} 2)$ under water stress $50 \% \mathrm{FC}$. This result indicated that $\mathrm{H} 2$ had the greatest green biomass and could be considered as a drought tolerant genotype. The optimal stages for measuring NDVI vary depending on the germplasm and environment. Breeding programs usually pay little attention to field observations prior to heading, as there is limited visual variation between different genotypes, but our results suggest the importance of early measurements of spectral indices from stem elongation to anthesis, since substantial differences were observed for NDVI. One important issue of using the vegetative indices is their nonlinear variation during vegetation specially under water stress, which results cleared in changes of correlation directions from negative to positive depending on the crop stage. This requires a better understanding of what biological processes and differences between the genotypes are reflected at the specific time of measurement. In general, as the technology develops, more advanced sensor tools will be available and may improve the efficiency of selection for stress conditions (Bayoumi et al., 2015).

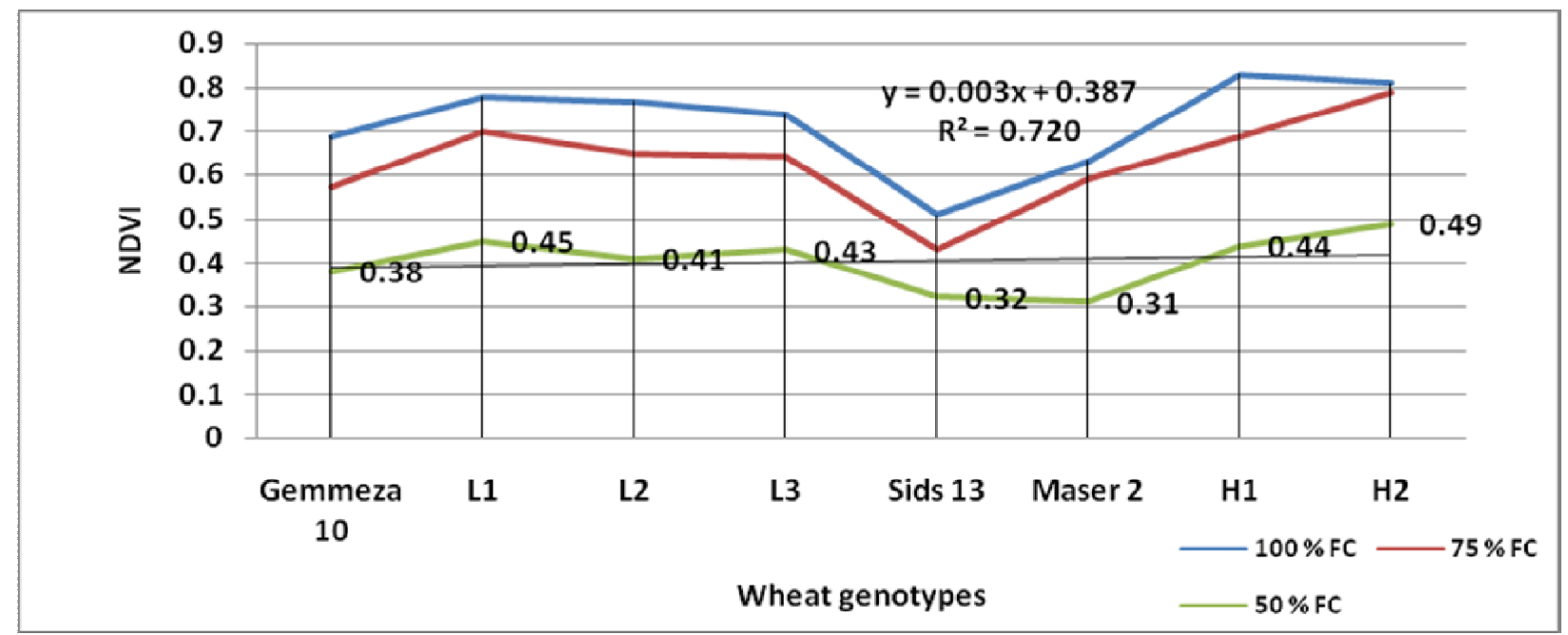

Fig. (3): The effect of water stress on NDVI for wheat genotypes for combined analysis

\section{Genetic behavior of wheat genotypes to water stress}

Results of genetic parameters of eco-physiological traits and yield under stress and non-stress conditions for wheat genotypes are illustrated in Table (3). The phynotypic coefficient of variability (PCV) was higher than the genotypic coefficient of variability and it increased under stress than non stress conditions. Under both environments the highest genotypic and phenotypic coefficients of variability were recorded for grain yield, total leaf area, plant height and spike length. Concerning the heritability values, it is clear that heritability estimates decreased under stress conditions than non stress conditions. Heritability values under non stress ranged from $41.4 \%$ to $84.5 \%$ for grain yield and relative water content respectively, while, the same traits under stress conditions ranged from $35.6 \%$ to $81.6 \%$, respectively. Genetic advance as percent of the mean was highest for RWC (41.3\%) and Spike length (31.6\%) while, the remaining traits showed a moderate to very low amounts of genetic advance. In generally the higher heritability estimates for these traits indicate that environmental factors did not greatly affect phenotypic variation of such characters. The knowledge of genetic variation and association between agronomic traits is regarded to support considerable help to maintain genetic improved to breeding program. This will assist plant breeders in choosing which agronomic traits should be used in their breeding programme. In the programme, high range of variability, heritability, genetic advance and positive correlation coefficient among traits could be an excellent tool for improving or selection genotype (Akbar et al., 2003).

\section{Effect of water deficit treatments on thermal canopy temperature}

Infrared thermal technique is used for selecting areas of interest; portions of images can then be analyzed to give either average temperatures or the frequency distribution of temperatures over the selected area. Such analysis for images has been taken both faceon to a canopy and along a row of plants (Fig. 4). These examples illustrate the different temperature distributions between various stressed canopies; with sever water stress canopies displaying a far wider and higher range of temperature variation. The 3D frequency distributions were clearly different with the sever water stress side tending to have a greater variance of temperature. Figure (4) showed that, the mean temperatures for wheat genotypes under $50 \% \mathrm{FC}$ were $22.3^{\circ} \mathrm{C}$, while the maximum and minimum temperature were $24.9^{\circ} \mathrm{C}$ and $19.9^{\circ} \mathrm{C}$, respectively. Under water stress $75 \% \mathrm{FC}$, the maximum temperature was $23.1^{\circ} \mathrm{C}$ ), the minimum temperature was $19.6^{\circ} \mathrm{C}$ with average $21.1^{\circ} \mathrm{C}$. There were clear differences in the temperature variability due to water stress treatments and genotypes effect. High-resolution thermal imaging can also help to characterize morphology and plant 
architecture traits that are important for selecting superior varieties for different environmental conditions (Chéné et al., 2012). For canopies with randomly oriented leaves, the information on temperature frequency distributions obtained from imagers would allow application of (Fuchs, 1990) method for detecting stomatal closure The greater sensitivity of leaf temperature to stomatal conductance for water stress as compared with non stressed leaves suggested that it might be best to use water stress leaves for the estimation of stomatal conductance from thermal data.

Table (3): The genetic parameters of phenotypic and genotypic coefficient of variability (PCV and GCV), heritability (h2) and genetic advance (\%) of the mean (GA \%) of wheat genotypes under non stress and stress conditions for combined analysis.

\begin{tabular}{lcccccccc}
\hline \multirow{2}{*}{ Characters } & \multicolumn{3}{c}{$\mathbf{1 0 0} \%$ FC } & \multicolumn{5}{c}{$\mathbf{5 0} \%$ FC } \\
\cline { 2 - 8 } & PCV \% & GCV \% & h2 \% & GA \% & PCV \% & GCV \% & h2 \% & GA \% \\
\hline Plant height & 43.6 & 20.4 & 50.1 & 14.4 & 45.2 & 29.8 & 49.2 & 10.5 \\
Awn Length & 12.8 & 9.4 & 60.2 & 16.1 & 13.5 & 10.4 & 58.6 & 12.4 \\
No. of tillers & 14.2 & 10.3 & 62.1 & 20.3 & 17.7 & 10.9 & 60.5 & 15.4 \\
Total leaf area/plant & 37.8 & 33.6 & 43.8 & 4.5 & 38.6 & 31.6 & 40.1 & 4.2 \\
Relative water content \% & 6.8 & 5.4 & 84.5 & 36.4 & 15.9 & 12.8 & 81.6 & 41.3 \\
Spike Length & 33.5 & 27.9 & 76.2 & 35.4 & 35.4 & 28.6 & 74.3 & 31.6 \\
1000-KW & 11.8 & 8.8 & 70.2 & 12.3 & 13.6 & 9.2 & 68.2 & 11.4 \\
Grain Yield & 72.6 & 44.5 & 41.4 & 7.6 & 73.8 & 46.2 & 35.6 & 4.9 \\
\hline
\end{tabular}

\section{Thermal indices}

The various water stress treatments created a wide range of water statuses as reflected by stomatal conductance and CWSI values which calculated from leaf temperature. Plant water status is normally evaluated at the time of maximum expression of stress. In wheat, mid-day is an acceptable measure of plant water status. Leaf canopy temperature was used to calculate stress index (CWSI) and stomatal conductance $\left(\mathrm{I}_{\mathrm{G}}\right)$ for wheat genotypes (Table 4). The genotypic differences in canopy temperature increased under high water stress ( $50 \%$ FC). Significant differences between treatments in the absolute temperatures of areas of canopy suggest that this may be an effective method of distinguishing stressed from non stressed plants. However, in other situations, where there are no randomized treatments to compare, such as monitoring a plant canopy over time for the purposes of irrigation scheduling, it can be difficult to distinguish increasing plant stress from an increase in air temperature. The use of references is designed to eliminate such a problem. Leaf temperature $\left(\mathrm{T}_{\text {leaf }}\right)$ varied between water stress treatments and among the wheat genotypes within the same water treatment. Where, $\mathrm{T}$ leaf was ranged from 21.9 to $25.3^{\circ} \mathrm{C}$ for $50 \%$ FC treatment. Similar observations were noticed for other water treatments; indicating that the other physiological mechanism could be influenced on the behavior of genotypes due to water stress and subsequently Leaf temperature was affected. Recently, Costa et al. (2012) observed different $T_{\text {leaf }}$ and $\mathrm{I}_{\mathrm{G}}$ phenotypes between grapevine varieties with similar water status, suggesting different types of stomatal regulation.
Leaf temperature is an indicator of stomatal conductance, automating the analysis of thermal images acquired with long-wave infrared (IR) sensors The $\mathrm{I}_{\mathrm{G}}$ ranged from $0.56(\mathrm{H} 2)$ to 0.70 (Gemmeza 10). While, the CWSI values were ranged from $0.33(\mathrm{H} 2)$ to 0.416 (Gemmeza 10). This CWSI allows relating crop's temperature to the maximum and minimum values possible under similar environmental conditions. The higher the CWSI, the greater the crop stress is assumed by Yuan et al. (2004), Testi et al. (2008) and Bayoumi et al. (2014) for example, found CWSI to be inversely correlated with leaf water potential.

Significant genetic variability of transpiration response to vapor pressure deficit was found amongst wheat genotypes. Isohydric species maintain nearly constant leaf water potential during the day, by stomatal closure, whereas in anisotrophic species the water potential decreases with evaporative demand (Tardieu and Simonneau, 1998). However, some plants can change from anisohydric to isohydric behavior with increasing soil water deficit (Collins et al., 2010).

Wheat and barley show anisohydric behavior with increasing water deficit. Leaf water potential of wheat and barley decreased as the root water potential decreased, and osmotic adjustment resulted in turgor being maintained. Stomatal conductance can be a reliable indicator of growth rate response to stress, and thermal imaging is a possible screening method for both the laboratory and field. Genetic variation in response to stress can be exploited in annual crops if irrigation water is available. Tolerant (small stomatal response) lines could be useful for irrigation in arid conditions. Sensitive (large stomatal response) lines could be useful for long-term drought. 
Table (4): Average temperatures $\left({ }^{\circ} \mathrm{C}\right)$ and stress indices for wheat genotypes under various water stress from combined analysis.

\begin{tabular}{|c|c|c|c|c|c|c|c|c|c|}
\hline \multirow[b]{2}{*}{ Genotypes } & \multicolumn{3}{|c|}{$\mathbf{T}_{\text {leaf }}$} & \multicolumn{2}{|r|}{$\mathbf{T}_{\text {wet }}$} & \multirow{2}{*}{$\begin{array}{c}T_{\text {dry }} \\
50 \% \\
\text { FC }\end{array}$} & \multirow{2}{*}{$\begin{array}{c}\mathbf{I}_{\mathrm{G}} \\
\mathbf{5 0} \% \\
\mathrm{FC}\end{array}$} & \multicolumn{2}{|c|}{ CWSI } \\
\hline & $\begin{array}{c}100 \% \\
\text { FC }\end{array}$ & $75 \%$ FC & $\begin{array}{c}50 \% \\
\text { FC }\end{array}$ & Mean & $50 \%$ FC & & & $\begin{array}{c}75 \% \\
\text { FC }\end{array}$ & $\begin{array}{c}50 \% \\
\text { FC }\end{array}$ \\
\hline Gemmiza 10 & 18.51 & 22.9 & 25.3 & 22.2 & 19.8 & 30.2 & 0.89 & 0.70 & 0.67 \\
\hline L1 & 18 & 21.9 & 23.8 & 21.2 & 18.4 & 29.1 & 0.98 & 0.67 & 0.50 \\
\hline L2 & 17.9 & 21.8 & 22.7 & 20.8 & 18.4 & 29.1 & 1.49 & 0.68 & 0.60 \\
\hline L3 & 17.8 & 21.5 & 22.4 & 20.6 & 18.2 & 27.3 & 1.17 & 0.64 & 0.54 \\
\hline Sids13 & 18.75 & 22.8 & 25.9 & 22.5 & 19.2 & 31.1 & 0.78 & 0.70 & 0.44 \\
\hline Maser 2 & 18.6 & 22.2 & 25.7 & 22.2 & 19 & 29.4 & 0.55 & 0.69 & 0.36 \\
\hline H1 & 17.6 & 20.9 & 22.1 & 20.2 & 17.5 & 26.4 & 0.93 & 0.62 & 0.48 \\
\hline H2 & 17.4 & 20.3 & 21.9 & 19.9 & 17.2 & 24.2 & 0.49 & 0.56 & 0.33 \\
\hline Mean & 18.1 & 21.8 & 23.7 & & 18.5 & 28.4 & 0.9 & 0.7 & 0.5 \\
\hline LSD & 1.01 & 0.98 & 1.23 & & 0.05 & 0.31 & 0.08 & 0.127 & 0.114 \\
\hline
\end{tabular}

$\mathbf{T}_{\text {leaf, }}$ leaf canopy temperature; $\mathbf{T}_{\text {wet }}$, wet leaf temperature; $\mathbf{T}_{\text {dry }}$, dry leaf temperature; $\mathbf{I}_{\mathbf{G}}$, stomatal conductance; $\mathbf{C W S I}$, crop water stress index

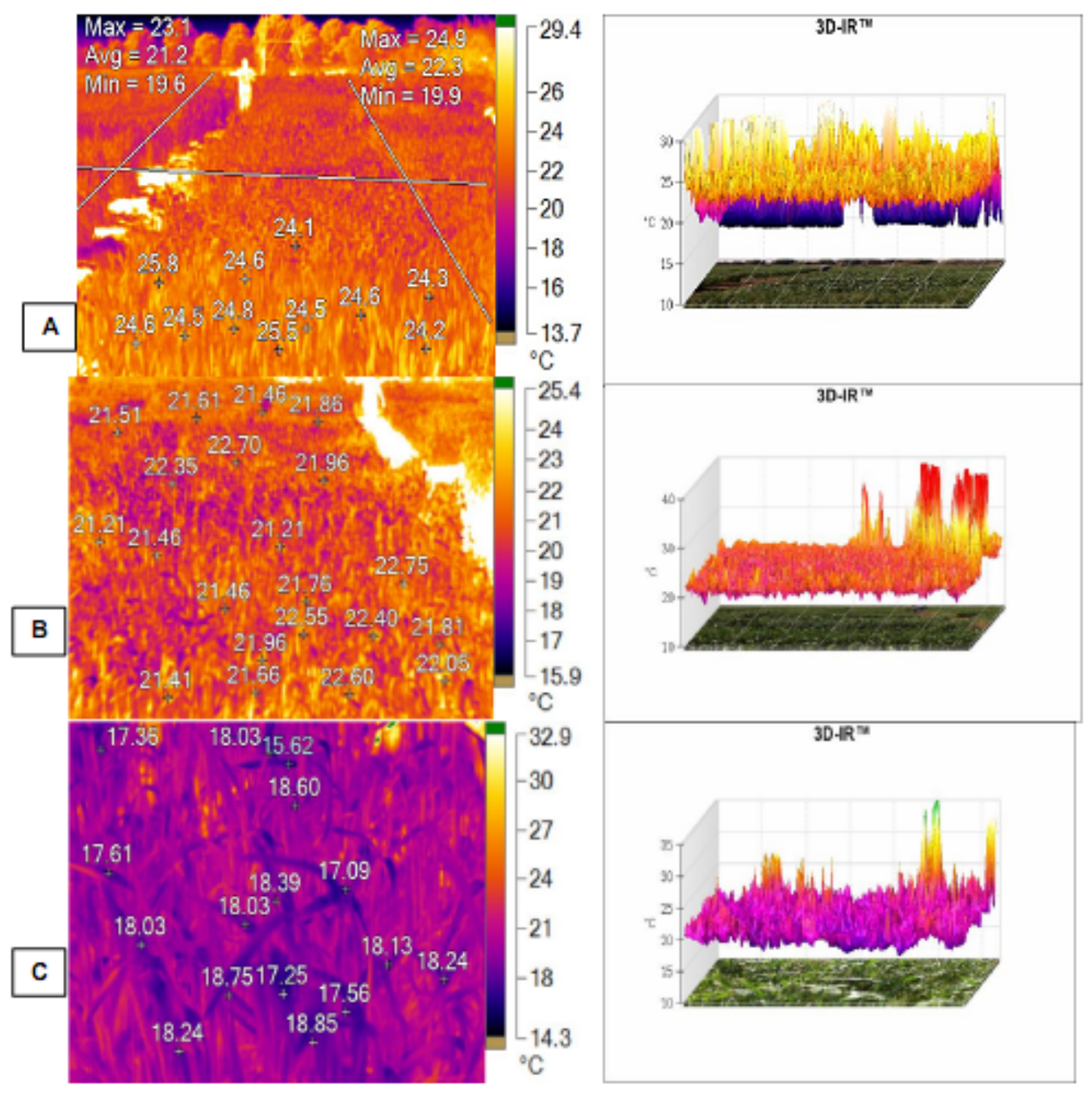

Fig. (4): Thermal images of section for wheat canopy along with $3 \mathrm{D}$ frequency distribution when analyzing the images under $50 \% \mathrm{FC}(\mathrm{A}), 75 \% \mathrm{FC}(\mathrm{B})$ and $100 \% \mathrm{FC}(\mathrm{C})$ treatments 


\section{CONCLUSION}

Drought stress leads to a wide range of physiological responses in addition to the obvious reductions in photosynthesis, stomatal conductance, and leaf growth. These include changes in spectral reflectance and fluorescence related to alter light harvesting and biochemistry caused by oxidative stress. Thermal imaging and NDVI can reduce the time needed for screening wheat genotypes to drought -based estimation of growth performance. These techniques can be further complemented by some eco-physiological traits, which directly visualize inherently fluorescing compounds that accumulate under stress conditions. Generally, it is concluded that new high-throughput imaging technologies in controlled environments can provide a useful way of screening large numbers of genotypes and identifying small differences in growth rate or expression of certain traits.

\section{REFERENCES}

Akbar, M., T. Mahmood, M. Yaqub, M. Anwar, M. Ali and N. Iqbal (2003): Variability, correlation and path coefficient studies in summer mustard (Brassica juncea L.). Asian J Pl. Sci., 2: 696698.

Bayoumi, T. Y., Soad A. Mahmoud, M. S. H. Yousef and M. A. Emam (2015). Detecting drought tolerance in wheat genotypes using highthroughput phenotyping Techniques. The $3^{\text {th }}$ international conference of advanced applied science (ICAAS-III) Hurghada, Egypt. 101-116.

Bayoumi, T. Y., A. A. Aly and S. El. M. M. Ammar (2002). Ecophysiological characters as screening criteria for drought tolerance in durum wheat genotypes. J of Agric. Res.,SCU(1) 1-7.

Bayoumi, T. Y., S. El-Hendawy, M. S. Yousef, M. A. Emam and S. A. Okasha (2014). Application of infrared thermal imagery for monitoring salt tolerant of wheat genotypes. Journal of American Science, 10(12): 227-234.

Blum, A. (1986). The effect of heat stress on wheat leaf and ear photosynthesis, J. Exp. Bot., 37:111-118.

Brenes-Arguedas, T., A. Roddy, P. Coley and T. Kursar (2011). Do differences in understory light contribute to species distributions along a tropical rainfall gradient? Oecologia, 166: 443456.

Chéné, Y., D. Rousseau, P. Lucidarme, J. Bertheloot, V. Caffier, P. Morel, E. Belin and F. ChapeauBlondeau (2012). On the use of depth camera for $3 \mathrm{D}$ phenotyping of entire plants. Computers Electronics and Agriculture, 82: 122-127.

Cohen, Y., V. Alchanatis, M. Meron, S. Saranga and J. Tsipris (2005). Estimation of leaf water potential by thermal imagery and spatial analysis. Journal of Experimental Botany, 56: 1843-1852.

Collins, M., S. Fuentes and EWR Barlow (2010). Partial rootzone dryingand deficit irrigation increase stomatal sensitivity to vapor pressure deficit in anisohydric grapevines. Functional Plant Biology, 37: 128-138.
Costa, J. M., M. F. Ortuño, C. M. Lopes and M.M. Chaves (2012). Grapevine varieties exhibiting differences in stomatal response to water deficit. Functional Plant Biology, 39: 179-189.

Dawson, T.E., S. Mambelli, A.H. Plamboeck, P.H. Templer, K.P. Tu (2002). Stable isotopes in plant ecology. Annu. Rev. Ecol. Syst., 33: 507.

Ehdaie, B., J. G. Waines and A. E. Hall (1988). Differential responses of landraces and improved spring wheat genotypes to stress environments. Crop Sci., 28: 838-842.

Fuchs, M. (1990). Infrared measurement of canopy temperature and detection of plant water stress. Theoretical and Applied Climatology, 42: 253261.

Hallauer, A. R. and J. B. Miranda (1988). Quantitative genetics in maize breeding. $2^{\text {nd }}$ ed. Iowa State Univ. Press, Ames. 71-76.

Idso, SB. (1982). Non-water stressed baselines: a key to measuring and interpreting plant water stress. Agricultural Meteorology, 27: 59-70.

Jackson, P., M. Robertson, M. Cooper and G. L. Hammer (1996). The role of physiological understanding in plant breeding; from a breeding perspective. Field Crop Res., 49: 11-37.

Jones, H. G., R. Serraj, B. R. Loveys, L. Xiong, A. Wheaton and A. H. Price (2009). Thermal infrared imaging of crop canopies for the remote diagnosis and quantification of plant responses to water stress in the field. Functional Plant Biology, 36: 978-979.

Jones, H. G., M. Stoll, T. Santos, C. de Sousa, M. M. Chaves and O. M. Grant (2002). Use of infrared thermography for monitoring stomatal closure in the field: application to grapevine. Journal of Experimental Botany, 53: 2249-2260.

Jones, HG and R. A. Vaughan (2010). Remote sensing of vegetation: principles, techniques and applications. Oxford, UK: Oxford University Press. 35-46.

Jones, H. G. (1999). Use of thermography for quantitative studies of spatial and temporal variation of stomatal conductance over leaf surfaces. Plant, Cell and Environment, 22: 1043-1055.

Kursar, T. A., B. M. J. Engelbrecht, A. Burke, M. T. Tyree, B. Ei Omari and J. P. Giraldo (2009). Tolerance to low leaf water status of tropical tree seedlings is related to drought performance and distribution.Funct Ecol, 23: 93-102.

Quarrie, S. A., J. Stojanovic and S. Pekic (1999). Improving drought resistance in small-grained cereals: A case study, progress and prospects. Plant growth regulation, 29: 1-21.

Ritchie, S. W., H. T. Nguyen and A. S. Holaday (1990). Leaf water content and gas-exchange parameters of two wheat genotypes differing in drought resistance. Crop. Sci., 30: 105-111.

Schonfeld, M. A., R. C. Johnson, B. F. Carver and D. W. Mornhinweg (1988). Water relations in winter wheat as drought resistance indicators. Crop. Sci., 28: 536-541. 
Snape, J. W., K. Butterworth, E. Whitechurch and A.J. Worland (2001). Waiting for fine times: the genetics of flowering time in wheat, Euphytica, 119: 185-190.

Steel, R. G. D, J. H. Torrie and D. A. Diskey (1997). Principles and Procedures of Statistics: A Biometrical Approach; $3^{\text {rd }}$ ed. McGraw-Hill, New York. 185-191.

Tardieu, F. and T.Simonneau (1998). Variability among species of stomatal control under fluctuating soil water status and evaporative demand: modelling isohydric and anisohydric behaviors. Journal of Experimental Botany, 49: 419-432.
Testi, L, D. A. Goldhamer, F. Iniesta and M. Salinas (2008). Crop water stress index is a sensitive water stress indicator in pistachio trees. Irrigation Science, 26: 395-405.

Wilcox, J. and D. Makowski (2014). A metaanalysis of the predicted elects of climate change on wheat yields using simulation studies. Field Crops Research, 156: 180-190

Yuan, B. Z., J. Sun and S. Nishiyama (2004). Effect of drip irrigation on strawberry growth and yield inside a plastic greenhouse. Biosystems Engineering, 87: 237-245.

\footnotetext{
الصور الحرارية كطريقة جديدة مع الصفات الإيكوفسيولوجية للتحكم في الإجهاد المائي للقمح

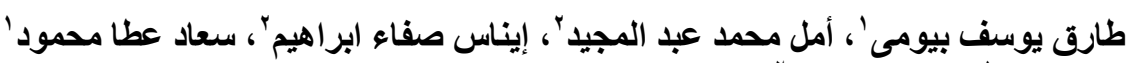

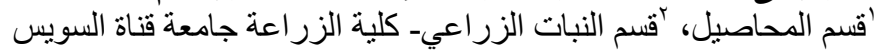

درس الارتباط بين التصوير الحراري والصفات الخاصة بالتحمل للجفاف منل وجود السفا ودليل الاختلاف في النمو الخضري و المحتوى المائي للأوراق (RDVI) و مساحة الوريز (RWC)

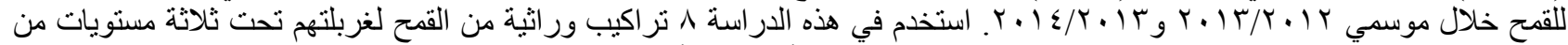

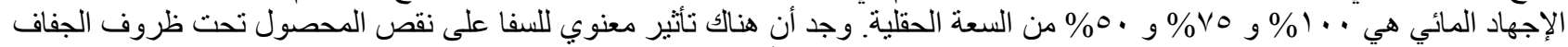

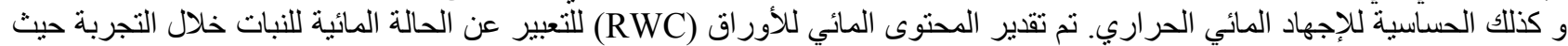

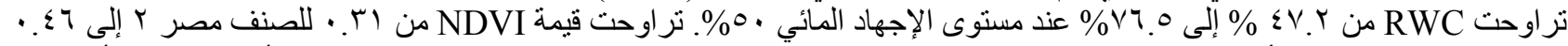

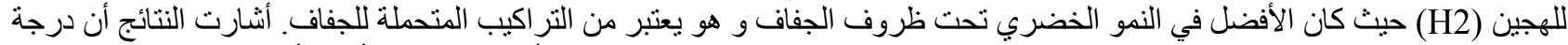

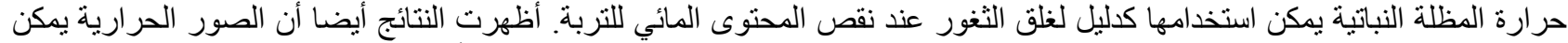

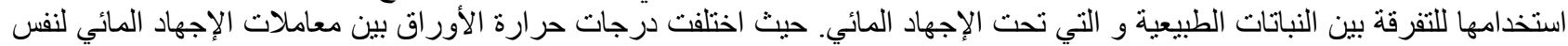

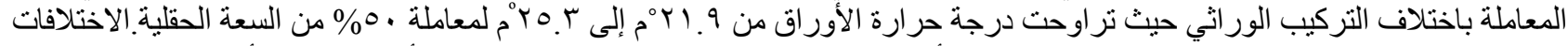

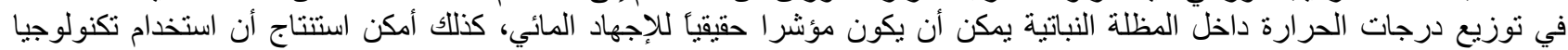

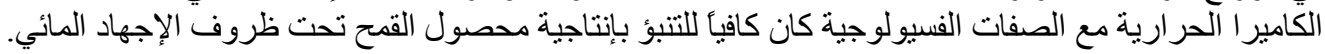

